\title{
CMA transformation initiative scrutinized
}

I $\mathrm{s}$ it radical change? Mere code for fatter bank accounts for physicians? So broadly defined as to be meaningless?

Or is it tactically brilliant in giving people something they want - such as national pharmacare - while squeezing in a few things that may be less palatable - such as more private delivery of health care services?

The Canadian Medical Association's (CMA) preliminary blueprint for "transformative" change of the health care system may be all of the above, if the response from delegates to the association's 142nd annual meeting in Saskatoon, Saskatchewan, is any indication.

Asked to comment on the work-inprogress, doctors marvelled at its breathtaking scope, while beginning to pick apart elements of the plan.

Wary of the blueprint's proposal for more physician accountability, some doctors said they were fearful of evaluations. Others were concerned about the plan's impact on rural or small health care facilities, or its potential cost, whether financial or in terms of the erosion of medicare. Still others grumbled that the plan's "patient first" theme appears to imply the troubling proposition that patients are not now being placed first.

Others still, such as Saskatchewan delegate Dr. Peter Barrett, argued that doctors must lead change because politicians appear unable or unwilling to do so.

Asked whether the plan was deliberately crafted to be all-encompassing in order to make it potentially more politically saleable, CMA president Dr. Robert Ouellet told reporters that while the initiative has many dimensions, its primary objective is to reduce wait times.

It's not an all-or-nothing situation, Ouellet said. "It's the way we will see things. Maybe we can't implement everything at the same time. Maybe next year, we will say, we will have to

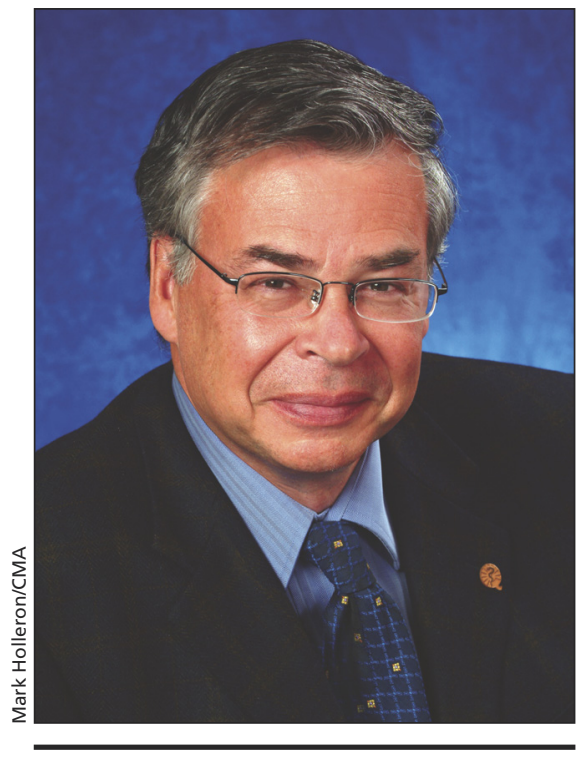

CMA President Robert Ouellet toured several European countries in a quest for models for sustainable funding of medicare.

start with one point. But ... I don't want to wait 25 years to see some change in our system. Look at what they're doing in the US. It's a bold change that they want to do. We need to do the same thing."

Ouellet said the plan is a work-inprogress and encouraged physician delegates to share their ideas.

"Transform means to go further," Ouellet added.

Perhaps it means too much, counters Canadian Doctors for Medicare Chair Dr. Danielle Martin.

The notion of transformation of the Canadian health care system is illdefined, she says. "Part of the problem is everyone is interpreting the word to mean what they want it to mean. ... We're not all operating from a common definition."

"To me the word transformation implies a total and complete alteration of the most fundamental parts of the system and I don't think that's necessary. I think fundamentally the system is currently based on the right principles."

As outlined to delegates, the plan is predicated on five goals for a systemic overhaul of the system. These goals are: "Building a culture of patient-centred care; Incentives for enhancing access and improving quality of care [including activity-based hospital funding and pay-forperformance compensation for physicians]; Enhancing patient access across the continuum of care [including national pharmacare, long-term and home care programs]; Helping providers help patients [including electronic record keeping and training more doctors]; and Building accountability/responsibility at all levels."

Several delegates, including Dr. Mark Masterson of British Columbia and Canadian Association of Internes and Residents President Dr. Roona Sinha, lamented the blueprint's nearabsence of measures aimed at training the next generation of Canadian doctors. Yet, they will be the "true agents of change," Masterson said, adding that activity-based funding of hospitals must not serve to scale-back training programs at teaching hospitals.

Northwest Territories delegate Dr. Andrew Kotaska expressed concern that a transformed medicare system might serve to promote queue-jumping by patients, as well as an exodus of physicians from public to private health care institutions, "as in Australia and the United States."

Dr. Amy Hendricks, also a Northwest Territories delegate, said the blueprint must seek to redress the chronic shortage of family physicians if it is to truly address the needs of Canadians and relieve the workload of medical specialists, particularly those in rural and remote areas of Canada.

Perhaps the most compelling argument regarding activity-based funding was presented by British Columbia delegate Dr. Trina Larsen Soles. Small hospitals, like the one she works at in Golden, have already been forced to reduce the number of beds (from 25 to eight) and they couldn't possibly sur- 
vive in a so-called competitive environment, given their small population bases. "A lot of us will be closed."

Ouellet countered with decentralist arguments, saying transformation must be tailored to unique conditions of each community, so smaller hospitals could still get block funding, while larger ones in major cities would face the rough-and-tumble of competition.

The blueprint is broadly based on information garnered during Ouellet's recent tour of Belgium, Denmark, France, the Netherlands and the United Kingdom to identify suitable models for sustainable funding of medicare.

But Martin notes that there are several differences between Canada and European nations, including population density, taxation systems and physician-to-population ratios.

"When the issue that's being targeted in particular is wait times and the solutions that are particularly being proposed are activity-based funding and competition, then it really does become relevant what the context is because the physician-to-population ratio is so different. We're talking $50 \%$ more doctors per 1000 population [in some European countries]."

Hendricks noted that Canada's vast geography should also be a consideration. "As physicians, we're always encouraged to look at medical literature and decide whether a clinical trial can be generalized to a patient population. I'm concerned that the European comparison may not be generalizable to a country that's as vast as Canada."

In a special session on how to sell the plan to politicians and the general public, Peter Donolo, a partner in the market research and strategic communications consulting firm the Strategic Counsel and one-time director of communications for former Liberal prime minister Jean Chrétien, warned delegates there will be enormous obstacles to reforming medicare.

Those include public beliefs that medicare is a service to which Canadians are entitled and an "icon of Canada's national identify" that helps to distinguish the nation from its southern neighbour.
As well, reform proposed by doctors faces inherent public distrust as it is widely believed that when CMA speaks, it's either a "complaint about doctor shortages or doctor compensation, or for a greater element of privatization," he added.

If Canada's physicians are determined to lead reform, they should look to successful social marketing models that have been used to change public attitudes about things, such as the campaigns for seat belts or against smoking, Donolo argued. Alternatively, they should look to tax-based models, such as a registered medical savings plan to get Canadians into the habit of thinking they must make more of a personal contribution to financing their health care.

But making a compelling case will not be cheap, Donolo added, telling delegates they should be prepared to "put a lot of effort, a lot of bucks and lot of skin on the table." - Wayne Kondro, $C M A J$

DOI:10 1503/cmaj.109-3021 